\title{
Research on the Application of Group Cooperative Learning Model in the Teaching of Internal Medicine Nursing
}

\author{
Chen Xueyan ${ }^{1}$, Miao Beibei ${ }^{2}$ \\ Nursing College, Beihua University, \\ Jilin City, 132013
}

\begin{abstract}
To study the effect of application of cooperative learning mode in practical teaching in medical nursing students. In the 2013 grade senior high school, 6 classes of nursing undergraduates were selected, and 2 classes (control group and observation group) were selected as the research objects. The control group used the traditional teaching practice, teaching method was used in the observation group to learn centered teaching in group cooperation, comprehensive assessment scores of the students in both groups (the process of assessment, the final assessment) were compared. Through a questionnaire survey to evaluate the students' learning mode of cooperative group. The observation group of students during the examination scores were significantly better than the control group $(P<0.01)$; observation group give the students evaluation of cooperative learning mode for sure. The cooperative learning mode can improve students' self-learning ability, arouse students' enthusiasm, broaden the students' knowledge, cultivate students' team cooperation consciousness, improve the students' ability to analyze and solve problems.
\end{abstract}

Keywords-Group cooperative learning; Internal medicine nursing; Nursing education; Nursing teaching reform

\section{INTRODUCTION}

Medical nursing is one of the most important clinical courses of nursing specialty, patient care include disease and a number of specialist knowledge, at the same time a large amount of tedious, time, number of hours per week, leading to the traditional teaching practice under the dull atmosphere of the classroom, the traditional method of teaching makes students feel boring and obscure. To stimulate students' autonomy learning ability, cultivating students' critical thinking, this study tries to use cooperative learning mode in the teaching of medical nursing, and achieved good results. Now the report is as follows. Cooperation refers to the process of cooperation between two or more students or groups in order to achieve common goals. Cooperative learning group is in the system on the background of a kind of teaching methods in class teaching, namely after admitting the classroom teaching as the basic teaching organization form under the premise of teachers to students study group for important boost, by guiding team members to cooperate. Play a group of active function, improve individual learning motivation and ability to achieve the purpose of specific teaching task, changed the whole classroom teachers monopoly of information sources and the situation of students in a passive position, so as to stimulate the students' initiative and creativity, and therefore to full play.

\section{OBJECT AND METHOD}

\section{A. Research objects}

In the 2013 grade senior high school, 6 classes of nursing undergraduates were selected, and 2 classes (control group and observation group) were selected as the research objects. The observation group of 45 people, 4 boys and 41 girls, with an average age of 20.48 years; the control group of 43 people, 3 boys and 40 girls, with an average age of 21.23. Two classes of students gender, age was not statistically significant difference (P > 0.05), comparable.

\section{B. Teaching method}

1) Teaching arrangements

For a total of 126 hours of medical nursing training in our school 2013 edition of talent, this experiment selected the urinary system of patient care and nursing care of 2 patients in the Department of orthopedics nursing system, a total of 30 hours, the syllabus of two groups of students and teachers are the same. The control group 30 hours were used in traditional theory teaching; observation group of traditional theory teaching compressed to 10 hours, pathogenesis of disease only teach 20 hours, using cooperative learning mode in common learning clinical performance, nursing theory, nursing program of health education and so on.

\section{2) The scientific construction of study group}

The observation group 45 were divided into 5 groups, each group of 9 people, together to promote mutual learning, group members, and counselors and class research groups, to achieve quality, reasonable collocation strength. Each group selected 1 team leader, responsible for the overall coordination of group learning progress.

\section{3) Group cooperative learning}

The teacher according to the teaching content and curriculum design of cooperative learning problems, according to the head of the tasks assigned by the teacher allocation of members for the independent inquiry, the preparation stage after the leader called members of their respective report content and results of self inquiry, problem centered in the 
group discussion, group members combing the learning outcomes, recommend a representative study the results of the report in the form of PPT. The teachers to organize classroom 5 group representatives will group learning results to the class, teachers and students questioned the report after the evaluation or supplement, finally by the teachers around the teaching outline key, summary of difficulties is summed up, the content of teaching the whole section complete review and summary, teachers and students to complete the task of learning.

\section{Grades}

The comprehensive assessment process assessment and final assessment combining the two group students; questionnaires to the students in the observation group in anonymous way, students learning evaluation of team cooperation.

\section{Statistical methods}

Analysis by SPSS17.0 statistical software, using $x^{2}$ test, $t$ test, $\mathrm{P}<0.05$, the difference was statistically significant

\section{RESULTS}

A. Two groups of students comprehensive performance comparison (see Table 1)

TABLE I. COMPARISON OF COMPREHENSIVE SCORES BETWEEN THE TWO GROUPS (MEAN \pm S) SCORE

\begin{tabular}{|c|c|c|}
\hline GROUP & Process assessment results & Final examination results \\
\hline The control group, & $84.43 \pm 5.25$ & $87.25 \pm 9.14$ \\
\hline The observation group & $91.62 \pm 4.38$ & $89.48 \pm 5.61$ \\
\hline $\mathrm{t}$ & -8.274 & -1.356 \\
\hline $\mathrm{P}$ & $<0.01$ & $>0.05$ \\
\hline
\end{tabular}

B. The students in the observation group evaluated the group questionnaires, and the recovery rate and effective rate were cooperative learning model (see Table 2)

45 questionnaires were sent to the students in the observation group, 45 were recovered, 45 were valid

TABLE II. EVALUATION OF THE GROUP COOPERATIVE LEARNING MODEL $(\mathrm{N}=45)$ IN THE OBSERVATION GROUP $(\%)$

\begin{tabular}{ccc}
\hline Assessment Items & Yes & No \\
\hline Improve learning initiative & $42(93.33)$ & $3(6.67)$ \\
Improve communication and expression ability & $37(82.22)$ & $8(17.78)$ \\
Improve the team spirit of cooperation & $40(88.89)$ & $5(11.11)$ \\
Improve the ability to analyze and solve the problems & $41(91.11)$ & $4(8.89)$ \\
Improve the understanding of what you have learned & $41(91.11)$ & $4(8.89)$ \\
Attitude towards this teaching method & $38(84.44)$ & $7(15.56)$
\end{tabular}

\section{Discussion}

\section{A. The new teaching mode broadens the functions of nurses}

The nurse is not only the requirement of modern nursing concept of providers, communicator, more researchers, decision makers, which requires teachers to change the traditional education idea in the teaching process, constantly try new teaching methods, and let students actively participate in the teaching process. To guide students to participate in the bilateral activity of teaching and learning is the realization of teaching reform and improve the effective way of learning [1].
$100 \%$.

In cooperative learning, the role of the group is very important. In order to improve the team's cooperative learning efficiency, the group leader must be actively cultivated. First to work out the leader responsibility, let leader understand oneself not only to actively participate in cooperative learning, more need to be able to help the teacher to carry out the task group learning, arouse the study enthusiasm of team members, leading and coordinating group activities, comprehensive opinion, contact the teacher or foreign groups, etc. Secondly, we should teach the team leader some management methods and improve the ability of management. 
B. The group cooperative learning mode improves the students' self-learning ability and arouses their enthusiasm for self-study

Cooperative learning mode advocated independent inquiry, cooperative inquiry, students only through the initiative to read the information, analyze data in order to obtain information. This learning process to stimulate interest in learning, cultivate students' ability of self restriction, improve students' selflearning ability to acquire new knowledge [2]. The study of group cooperation is conducive to the cultivation of students' social adaptability. Firstly, the students adapt to each other in the small group, and by adapting to this small group, they gradually transition to adapt to the large group, thus cultivating the students' social adaptability. It is helpful to cultivate students' autonomy and independence. Team members are able to conduct adequate language, thought and daring training within the group. Through the communication between members of the group, they can boldly express their opinions through language. In the communication, gradually cultivate students to be able to interact with others and form their own independent opinions. It provides students with more training opportunities and promotes the all-round development of students. Team work in classroom teaching to create an environment for students to express themselves fully and provide more opportunities for each individual student. It is helpful to improve students' learning efficiency. Cooperative learning group, arouse the students' interest in learning, to make every student within the group set up center of collective consciousness, strengthen students' strong motivation to defend the collective honor and learning, the improvement of learning enthusiasm, it is the embodiment of our individual subjective initiative.

\section{The group cooperative learning mode broadens the students' knowledge, and raises the students' sense of teamwork}

Nursing is a theoretical and practical subject, nurses in addition to the basic theory, basic knowledge, basic skills, but also must constantly update their knowledge in order to adapt to the expansion of the development of the times, to meet the development of modern nursing needs. At the same time, the nursing work is a part of the whole clinical, to establish a good relationship with the doctor and the patients completed clinical tasks, group cooperative learning mode to take cooperative practice, is to provide a platform for students to learn cooperation [3].

In order to maximize student participation, members of the group have a relatively focused responsibility to play a specific role. If the group discusses the organizers, the recorder, the reference, the speakers, etc., then the roles will be exchanged, so that each member can get experience, exercise and improve from different positions. Encourage each team members to actively participate in to publish their views, listen to other students speak, timely supplement to modify their views, make everyone do in activities: will listen, expression, will be discussed. Make sure everything is done and everyone has something to do.

\section{The group cooperative learning model improves the students' ability to analyze and solve problems}

The modern demands of nursing nurse establish critical thinking mode and application of nursing procedures to provide holistic nursing care to patients, through the correct assessment of the patient, can be found in patients with existing or potential physiological, pathological, psychological problems, so as to assist doctors to effectively provide care and treatment. Group cooperative learning can increase students' professional knowledge in depth subject and breadth of knowledge, strain, training the students' thinking, communication, reasoning ability, and improve students' ability to solve problems [4].

The group cooperated to learn how to change the learning competition among students under the conditions of classroom teaching to change the relationship between "group learning" and "inter-group competition". Group learning will change the traditional teaching between teachers-students the one way communication into the multidirectional communication between teachers-student and students -students. It is not only improve the students' learning initiative and self control of learning, improve the teaching efficiency. It has promoted a good interpersonal relationship between students and promoted the development of the students' psychological quality and social skills improvement.

\section{CONCLUSION}

Carrying out the study is very important in medical nursing teaching in group cooperation, in line with the concept of modern nursing education and training objectives, and the traditional style, teacher centered teaching method, compared with the students passive lectures, group cooperative learning classroom atmosphere is good, the whole teaching process can be a very good theoretical knowledge and practice is helpful to cultivate students' initiative and creativity, to mobilize the students' enthusiasm in learning. It is necessary to carry out group cooperation and study, according to the actual level of teachers and students and the characteristics of teaching content, and not all kinds of teaching content should be suitable for group teaching mode. Simple teaching content enables students to learn independently and solve problems quickly. Complex learning needs to be taught. The key points can be adopted in the group cooperative learning mode, and the group cooperation study can focus on the wisdom of the people, which is beneficial to the problem solving and the cultivation of team spirit [5]. It can make students have an opportunity to expose themselves to simulated wards and clinical scenarios in school, which can not only improve the operational capability of students in clinical skills and clinical comprehensive thinking ability, but also stimulate their learning enthusiasm and potential [6]. However, there are some deficiencies in this experimental teaching model and they should be further studied and improved in the future practice. Teachers through typical cases to elaborate design problems, help to improve the teaching level of teachers, at the same time, the process of cooperative learning in students, teachers to guide students will design that knowledge is summarized, especially the progress and trends of knowledge of nursing care, nursing personnel trained with a strong ability to adapt, and get the employer universal praise Praise and praise. In conclusion, the group 
cooperative learning in the medical nursing teaching reform has achieved good teaching effect, it is worthy of promotion.

Teachers should act as mentors and motivators according to the difficulty of learning tasks and the actual situation of students. The teacher needs to observe the activity of the group, including the individual participation of each student; Need to go deep into the group, find the learning task completion, analyze their solution, discover their mistakes in time, in order to provide the necessary tips or correction, and timely answer questions from the students for individual group has unique insights and innovative thinking sparks, the teacher wants to give encouragement and support. In the whole process, the teacher should be taken is a friendly and constructive attitude and behavior, can neither too much intervention process and results of students thinking, nor the difficulty and the question of stand by for students. Students, teachers guide, communication, work to do, and good at capturing the spark to the language of language sense, fully mobilize students' perception, imagination and feelings, make them use intuition thinking and feelings, through read about a variety of forms such as animal language learning. Pay attention to read as the book, let the student to read, understand the reading, put into the emotional reading.

Group cooperative learning mode is an important learning method for students under the new curriculum concept. Effective cooperative learning can awaken the potential of students to sleep, activate sealed memories and open the claustrophobic mind. The group work together to learn from passivity to initiative, self-study, group communication, whole class discussion, teacher's advice and other organic integration. Students in the activities of mutual support, mutual cooperation, exert the principal role of students, mutual cooperation, the team's members between team cooperation and competition, arouse the enthusiasm for learning, excavate the potential of the individual learning, increases the amount of information, make the student improve together in complementary.

Under the new curriculum environment, teachers should always grasp the development of students as the main line, and our Chinese classroom teaching can radiate vitality. Facing all kinds of group cooperation in the form of practice, how to scientifically formulate cooperative learning evaluation standard, how to actively promote team cooperation through the scientific evaluation method as the main organization forms of learning, research, innovation and development of the small and medium-sized students, is subject to our further explore in practice.

\section{REFERENCES}

[1] Chen Shuangjian group cooperative learning in the teaching reform of Applied Science $>\mathbf{J}$ in "internal medicine nursing. The teaching of medical education, 2013, 10 (27):107 108.

[2] Yu Huiying. Group cooperative learning in nursing teaching in the application of J. China modern doctor, 2012, 50 (36):139 141.

[3] Yang Yuxia, Zhuang Dinah, Han Yan. Cooperative learning research and practice skills $>$ in the evaluation and practice of $\mathrm{J}$ in "nursing. Journal of Zhejiang Chinese Medicine University, 2012, 3 (36):317 319.

[4] Liang Tao. Training of students' problem solving ability in nursing clinical teaching [J]. Chinese Journal of nursing, 2001, 36 (4):302 - 304.

[5] Ouyang ronghua. Education technology. China Renmin University Press, 2011.

[6] Shi Chujun. Application of comprehensive SinMan in the teaching of clinical skills [J]. Northwest Medical Education, 2004, 12(2): 152-153. 